\title{
IDENTIFYING ORGANIZATIONAL INEFFICIENCIES WITH PICTORIAL PROCESS ANALYSIS (PPA)
}

\author{
David John Patrishkoff \\ E3 Extreme Enterprise Efficiency LLC, United States \\ E-mail: davepatrishkoff@aol.com
}

Submission: $30 / 04 / 2013$

Revisions: 18/05/2013

Accept: 24/07/2013

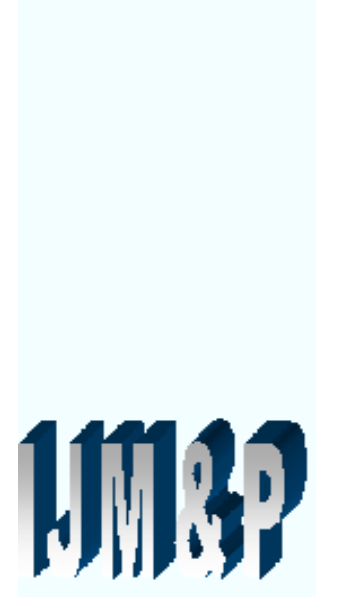

\section{ABSTRACT}

Pictorial Process Analysis (PPA) was created by the author in 2004. PPA is a unique methodology which offers ten layers of additional analysis when compared to standard process mapping techniques. The goal of PPA is to identify and eliminate waste, inefficiencies and risk in manufacturing or transactional business processes at 5 levels in an organization. The highest level being assessed is the process management, followed by the process work environment, detailed work habits, process performance metrics and general attitudes towards the process. This detailed process assessment and analysis is carried out during process improvement brainstorming efforts and Kaizen events. PPA creates a detailed visual efficiency rating for each step of the process under review. A selection of 54 pictorial Inefficiency Icons (cards) are available for use to highlight major inefficiencies and risks that are present in the business process under review. These inefficiency icons were identified during the author's independent research on the topic of why things go wrong in business. This paper will highlight how PPA was developed and show the steps required to conduct Pictorial Process Analysis on a sample manufacturing process. The author has successfully used PPA to dramatically improve business processes in over 55 different industries since 2004 .

Keywords: process mapping, business process management, business process reengineering. 
INDEPENDENT JOURNAL OF MANAGEMENT \& PRODUCTION (IJM\&P)

http://www.ijmp.jor.br

v. 4, n. 2, July - September 2013.

ISSN: 2236-269X

DOI: 10.14807/ijmp.v4i2.82

\section{INTRODUCTION}

"The Principles of Scientific Management" (TAYLOR, 1910) described the need for management to develop and document the science and definition for each element of an employee's work to replace the old "rule-of-thumb" way of working. Taylor firmly believed that it was up to management to determine the best way to do efficient work with the use of "time and motion" and other process analysis techniques.

Frank Gilbreth created the first structured method for documenting the flow of a process, which was presented to members of the American Society of Mechanical Engineers (ASME) in 1921 as a presentation titled "Process Charts - First Steps in Finding the One Best Way to do Work" (GILBRETH, 1921). Gilbreth was a bricklayer who later turned into an efficiency expert. He was consumed with the pursuit of improving the process of bricklaying. His passion for process efficiency launched the birth of the process mapping techniques that are used today. These process mapping tools were later integrated into industrial engineering curricula. In 1947, ASME adopted a set of symbols derived from Gilbreth's original work as the ASME Standard for Process Mapping.

This paper will show how that PPA is a continued evolution of the process mapping techniques that Taylor and Gilbreth started. It incorporates Taylor's Principles through an expanded version of standard process mapping, while assuring management involvement. Using PPA during business process analysis and mapping events is an enlightening and often enjoyable experience for the participants because it allows all of the issues in a manufacturing process and the surrounding enterprise to be openly discussed and assessed. This effort should focus on blaming the process and not the people in the process. When facilitated properly, all inefficiencies, waste risks are identified using the additional 10 layers of analysis in a process mapping exercise, which are added to a detailed process map, one layer at a time.

The author has been able to identify 54 organizational elements of risk assigned to 5 tiers of risky chain reactions to explain almost every human-made negative outcomes or disaster in business. A wide array of unpublished business 
DOI: 10.14807/ijmp.v4i2.82

cases with negative outcomes has been studied by the author as well as many other highly publicized human-initiated disasters, of which a small sampling is listed below:

- The Iroquois Theatre Fire Of 1903 (BRANDT, 2003)

- Sinking of sank the Titanic in 1912 (MCCARTY, 2008)

- Great Chinese Famine (1958-1961) (DIKOTTER, 2010)

- The USS Indianapolis Sinking in 1945 (THE USS INDIANAPOLIS STORY, 1998)

- Banqiao Reservoir Dam failure, China, in 1975 (XINHAU, 2005)

- NASA Space Shuttle Challenger disaster in 1986 (ROGERS,1986)

- Alaska Airlines Flight 261 crash in 2000 (NTSB, 2002)

- Petrobras 36 Oil Rig sinking in 2001 (WANDER, 2008)

- NASA Space Shuttle Columbia disaster in 2003 (GEHMAN, 2003)

- Deepwater Horizon Oil Spill in the Gulf of Mexico in 2006 (GRAHAM AND REILLY, 2012)

When large clusters of 54 available Inefficiency and risk Icons are assigned to specific process steps within a process map, this is a visual signal that highlights the need for dramatic process re-engineering in specific areas. The Inefficiency Icons represent organizational weaknesses that are part of 5 tiers of destructive chain reactions, that should be addressed to remove business risk, improve process efficiency and enhance customer satisfaction. The highly visual efficiency assessment of processes using PPA with its 10 layers of analysis allows the process analysis group to focus in on specific areas of the process that are not working well and are in need of immediate improvements.

The use of PPA will be demonstrated in this paper with the analysis of a simple generic manufacturing process shown in Figure 1. Each of the 10 layers of Pictorial Process Analysis will be added to assess this manufacturing process and bring it to life and determine its true efficiency levels. PPA identifies organizational barriers that are holding processes back from greatness.

The manufacturing process shown in Figure 1 is a very general process map, which, by itself, does not help us to assess its efficiency or opportunities for 
improvement. Ten layers of process analysis will be added to this simple process map to identify its true efficiency levels, which is necessary to critique, analyze, then optimize this process.

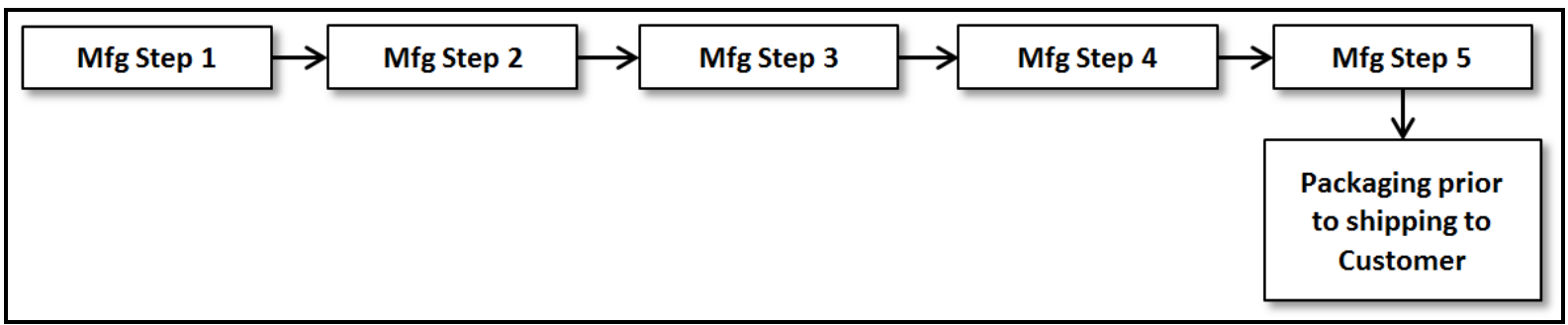

Figure 1: The simple manufacturing process used as a basis for analysis.

Source: The Author)

\section{RESEARCH METHODOLOGY}

The theories created, fine-tuned and applied in Pictorial Process Analysis has been successfully applied by companies in many industries to assess and address the internal barriers that hold them back from achieving process improvement breakthroughs. PPA was the result of 9+ years of Qualitative Research using inductive reasoning and the Grounded Theory Method (GTM) of research, usually applied in social work research (OKTAY, 2012). The author used GTM under an Applied Research agenda, with the goal of developing a practical an analytical method for modern companies to reduce risk, optimize their business processes and break their barriers to greatness. Three open-ended Applied Research \& GTM research-style "What's going on here" questions were asked at the beginning of the research that led to the discovery of the 5 chain reactions and their elements of risk:

- What are the common causes for business mediocrity, missed targets and disasters?

- What are the barriers that hold organizations back from greatness?

- What techniques could be created to identify the barriers to greatness and help to transform ordinary business processes into extraordinary ones?

These research questions were pointed at a select series of well documented serious business disasters and at businesses during dozens of Lean Kaizen events that the author facilitated. Many other business distress case studies were also subjected to this style of research. 
The details of business distress and disaster case studies were investigated, analyzed, coded for commonality of cause and further coded for theorized interactions and tiered chain reactions. The final working theories of the author's research identified five chain reaction waves that are capable of destroying any organization of any size and mission. There are many elements of risk inside each of these waves that have been identified that can be highlighted with the author's inefficiency and risk cards during detailed process mapping of individual business processes.

\section{THE THEORY OF SELF-DESTRUCTIVE CHAIN REACTIONS}

The result of the above mentioned research is a theory that is applied in PPA. This Theory states that most cases of organizational mediocrity, missed targets, business failures and even serious disasters are initiated by self-destructive and avoidable chain reactions that can be displayed and taught to professionals with the help of a unique deck of cards. This all-too-common scenario of escalating negative consequences is described below.

1. A series of Undisciplined Leadership Practices (16 Aces) can create...

2. flaws in the Work Environment (10 Kings), which can cause...

3. serious inefficiencies in Work Processes (21 Queens), which can cause...

4. a bad or failing Business Report Card (9 Jacks), which can cause...

5. a surprisingly faulty response to high risk situations (2 Jokers), for which the final outcome can be disastrous.

The 54 elements of risk in the 5 chain reactions (The Aces, Kings, Queens, Jacks and Jokers) are ever-present and can flair up at any time, without warning, if they are not consciously and continually assessed and addressed. The author has developed a USA Patent Pending Business Improvement Process that can be used to assess and address these elements of risk in chain reactions and break these barriers to greatness. PPA is very integral to that improvement process, which can be applied to any business process within any service or manufacturing company. 


\section{THE 10 LAYERS OF PICTORIAL PROCESS ANALYSIS}

A PPA event to improve a specific process is best conducted with the use of a cross-functional core team of process experts. Other process experts can be brought in to aid in the analysis as needed.

The 10 layers of Analysis used during PPA are listed below with a short explanation for each layer of analysis.

1. Identify and add specific "Swim Lanes" to the process map to show each functional area, department and customer that interacts with the manufacturing process.

2. Identify all correction, redo, rework and repair loops on the process map, even if they do not happen all the time. Show how many times these loops actually happen.

3. Identify how long (Low to high range) each process step takes. If there are extended waiting times, elevate the "Wait" step to an official process step so it can be targeted for improvement.

4. Identify and note what percent of VA (Value Added) activities are included in each process step. If the VA\% is less than $50 \%$, note it as red. If the VA\% is greater than $50 \%$, note it as green. Use innovation techniques to pursue $100 \%$ VA. Focus on possibilities and solutions, not excuses.

5. Note the estimated FTY (First Time Yield) of the process step and decision. In other words, what is the percent of the time that this process step is done right the first time?

6. Show Red dotted boxes to depict redo, fix, rework or repair loops in the process necessary to correct errors. Also note the number of times each redo loop happens.

7. Note if data is being collected for each process step that can be used for process efficiency and performance analysis purposes.

8. Show which of the 54 Inefficiency and risk Icons apply to this process and place them next to the process steps on the process map when they are present. This will highlight areas that need to be improved. 
9. Add a Total Process Efficiency Scorecard noting the ranges in efficiency from low end to high end, for the following criteria:

a. Total Process Lead Time (How long does the process take?)

b. Adjusted VA Time for the process (The time of the "true value" present in the process)

c. Total \% VA Time for the whole process (The true process value in $\%)$

d. RTY (Rolled Throughput Yield) for the whole process (The probability that a product will make it through the process without any issues)

10. Add a concise executive summary of the process analysis findings that PPA identified.

\section{- ANALYSIS LAYER \#1: ADDING SWIM LANES TO ALIGN TASKS TO DEPARTMENTS}

The PPA team will identify and add specific "Swim Lanes", shown in Figure 2, for each functional area, department and customer that interacts with the manufacturing process depicted in Figure 1. The purpose of this layer of analysis is to understand the interactions within and between different departments as well as interactions with customers. It might be discovered that certain department hand-offs create more delays and errors or that customers are poorly informed on information that is critical for them. This step will also help to determine if one department is too overloaded and if too many tasks are being done in series and not in parallel, which could slow down the process. 7 to 21 swim lanes will usually be required to represent manufacturing processes to capture all of the actual department activities and interactions. After this layer of analysis is completed for the current process, the team should brainstorm what improved department and customer interactions should look like. Complexity reduction should be a priority during this effort.

Joseph M. Juran was a strong proponent of cross-functional process excellence as defined in his "Juran Trilogy" (JURAN, 1988). Most processes cross different functional and department lines. Juran stressed the need for crossfunctional excellence, which includes quality planning, quality control and quality 
improvement in manufacturing processes. Management should not just let processes randomly develop on their own but help to design and manage processes to ensure an efficient, productive and competitive outcome.

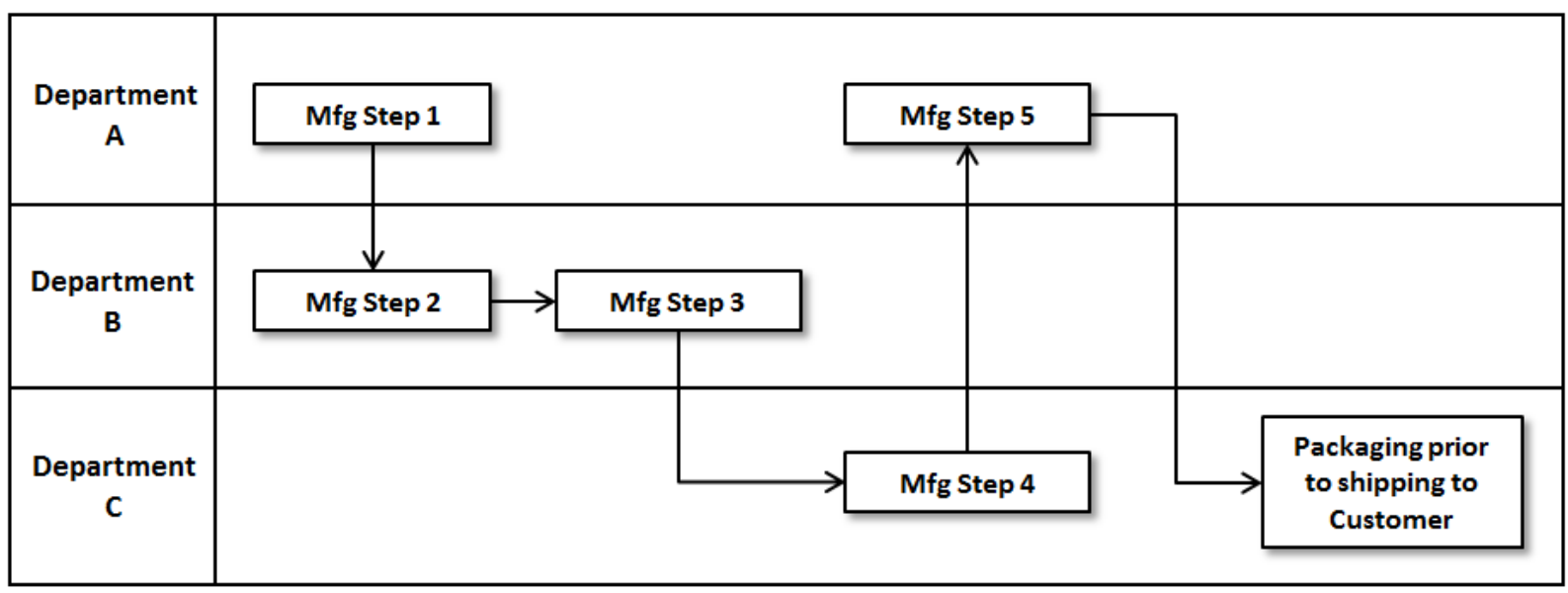

Figure 2: Swim lanes added to the previous process map.

Source: The Author

\section{- ANALYSIS LAYER \#2: IDENTIFY AND ADD ALL REDO AND CORRECTION LOOPS}

Add a description of all correction, redo, rework and repair loops to the process map, even if they do not happen all the time. Show what percent of the time they actually happen. Do the same for any decision point (diamond symbol). The purpose of this layer of analysis is to identify the amount of redo, rework and repair loops that are present. This will help you to assess the impact of all process decisions. Figure 3 shows what the manufacturing process looks like after the swim lanes; decision points and redo loops have been added to the process map. Whenever decision points are listed, note the percent of the time for each of the optional outcomes of the decision, as shown in Figure 3. After this layer of analysis is completed for the current process, the team should brainstorm how to minimize or eliminate the redo loops for the new and improved process. 


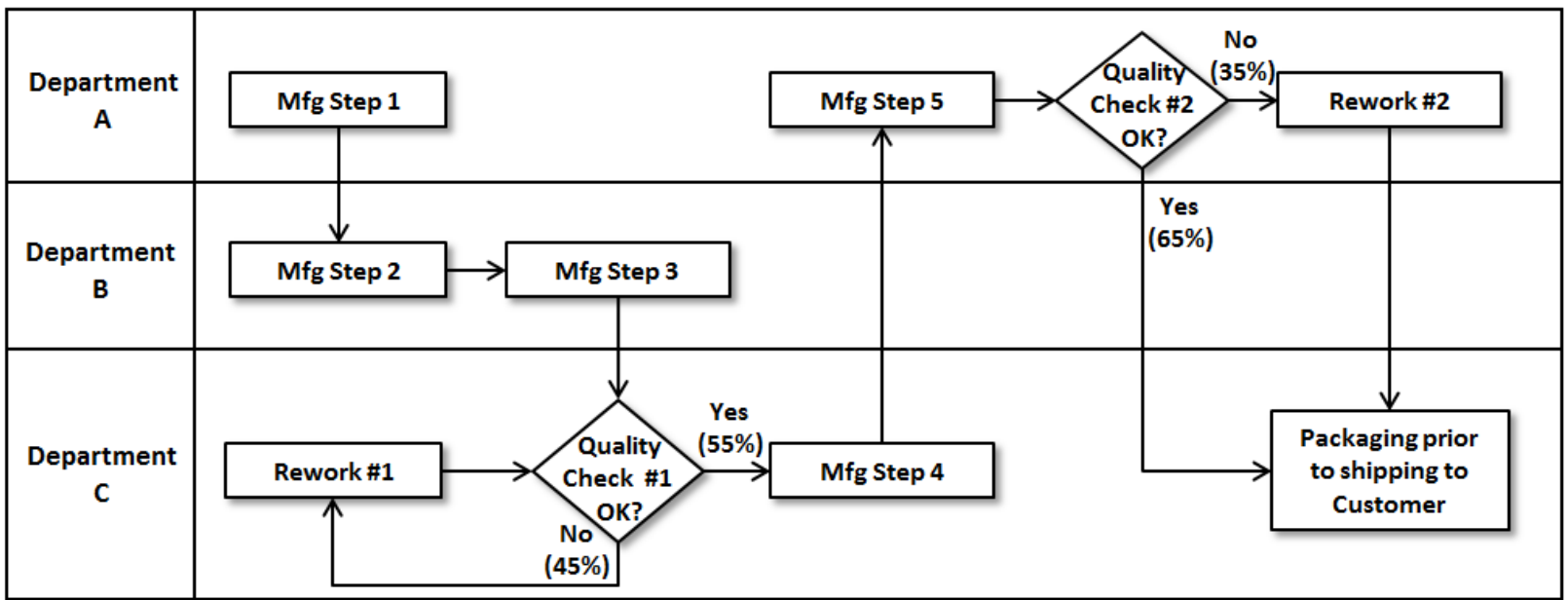

Figure 3: Correction, redo, rework and repair loops are added to the previous manufacturing process. (Source: The Author)

\section{- ANALYSIS LAYER \#3: IDENTIFY HOW LONG IT TAKES FOR EACH PROCESS STEP}

Add a time note on the process map for the duration of each process step and decision point. If there is variation in the time estimates, note the range of those times on the process map, from the best time to the worst time. The purpose of this layer of analysis is to identify the process steps that take too long so that the PPA team can brainstorm opportunities for improvement at the end of this analysis step. These new ideas will be implemented later when the new process is developed. Figure 4 shows what the process map now looks like when the times are added to the process steps. Unacceptable waiting periods are often identified during this analysis. When excessive waiting periods are identified, add them as an official process step. Do not just add those waiting times to the process step before or after the waiting periods in an indiscriminate manner.

Carrying out time studies for manufacturing processes is an important analysis step, which was identified as early as 1910 by Frederick Taylor and others. It is also an important aspect of Value Stream Mapping as originally defined by Shingeo Shingo (SHINGO, 1986) from Toyota and in later books from James Womack (WOMACK, 1996) and others. 


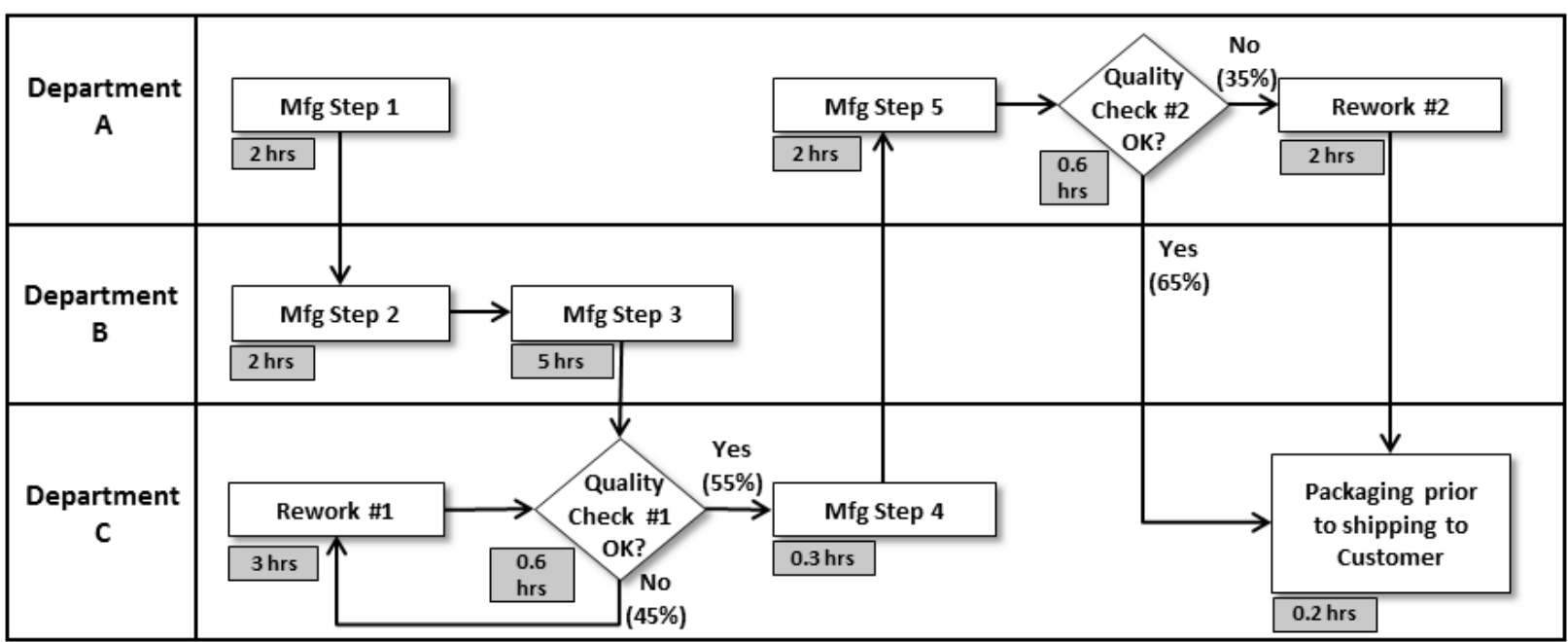

Figure 4: Notes are added to the previous process map to show how long each step in the process takes to complete.

Source: The Author

\section{- ANALYSIS LAYER \#4: IDENTIFY THE PERCENT OF VALUE ADDED ACTIVITIES FOR EACH PROCESS STEP}

Adam Smith was a Scottish economist and moral philosopher. He published the book "The Wealth of Nations" (SMITH, 1776), which argued that "productive labor" adds to the wealth of an entire nation and its economy, while "unproductive labor" does not. That drove the birth of the concepts for VA and NVA. VA work can be best defined as those activities that an external customer could fully appreciate as an activity that is fully worth the expense and effort of doing it. NVA activities are those that an external customer would not see any sense in doing and would deem as a "waste of time and effort". All forms of waiting and other forms of NVA, no matter how excusable they may seem, should be targeted for elimination. PPA teams are chartered to drive process innovation, not to make excuses.

The purpose of this layer of analysis is for the PPA team to estimate the percent of VA that is present for each process step and decision. These estimates for the percent of VA (Value Added) will be added to the process step as shown in figure 5. If the $\mathrm{VA} \%$ is less than $50 \%$, note it as red. If the $\mathrm{VA} \%$ is greater than $50 \%$, note it as green. The team must ask themselves 2 questions:

- Does this process or decision point add any true value to the final customer (\%VA external)?

- How efficient is each of the process steps (\%VA internal)? 
DOI: 10.14807/ijmp.v4i2.82

Efficiency estimates for each process step will have to be made. An example estimate follows.

- Example \#1: A certain manufacturing process activity is only $50 \%$ internally efficient but it is $100 \%$ important to the customer. In that case, the $\%$ VA would be $0.5 \times 1=50 \% \vee$ V.

- $\quad$ Example \#2: A certain manufacturing process activity is $95 \%$ internally efficient but it is totally unimportant $(0 \%)$ to the customer. In that case, the $\%$ VA would be $0.95 \times 0=0 \%$ VA.

The percent of value that should be added for each process step will be calculated as follows: The true efficiency of the internal activities (\% internal VA/100) multiplied by the perceived value of this process step in the eyes of the final customer (\% external VA/100). The results can range from $0 \%$ to $100 \%$.

It could be argued that quality checks are VA. In PPA, we argue, as Shingeo Shingo (SHINGO, 1986) and others did from Toyota (OHNO, 1988), that quality should be built into the product and manufacturing process and not inspected into the product. If manufacturing processes were rigorously error-proofed (poke-yoke), they would not need to be quality tested. Shingeo Shingo implemented this concept at Toyota and made it part of the Toyota Production System (SHINGO, 1986). Highly efficient manufacturing processes prevent mistakes from happening and do not rely on imperfect quality checks to sort out defective products. Figure 5 shows how \%VA information can be added to a PPA process map.

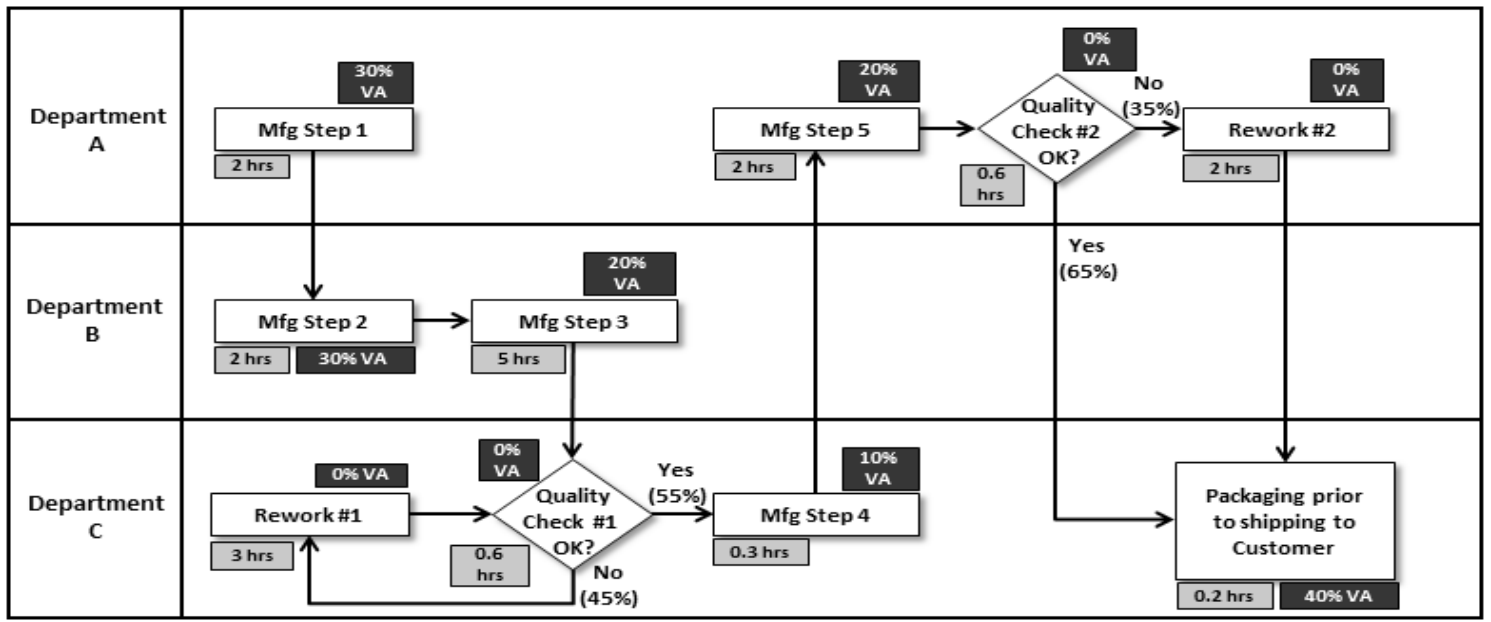

Figure 5: The percent VA for each process step is added to the previous process map.

Source: The Author 


\section{- ANALYSIS LAYER \#5: IDENTIFY THE FTY FOR EACH PROCESS STEP}

The estimated FTY \% (First Time Yield) should now be added for each of the process steps and decisions. The team is now being asked here to estimate what is the percent of the time that this process step is done right the first time. If exact data is not available for this required performance metric, the team should make a good estimate, which the team can agree on. The purpose of this activity is to identify process steps that are not done right the first time, which would require scrap, rework or customer complaints if the products or services were sent to the customer, in error, before being corrected. After adding this information to the process map, the team will scan the FTY notes made on the process map and focus on the lowest FTY entries and brainstorm how they might improve those situations in the new and improved process. These new ideas will be implemented later when the new process is developed. See Figure 6 for how this information is added to the PPA process map.

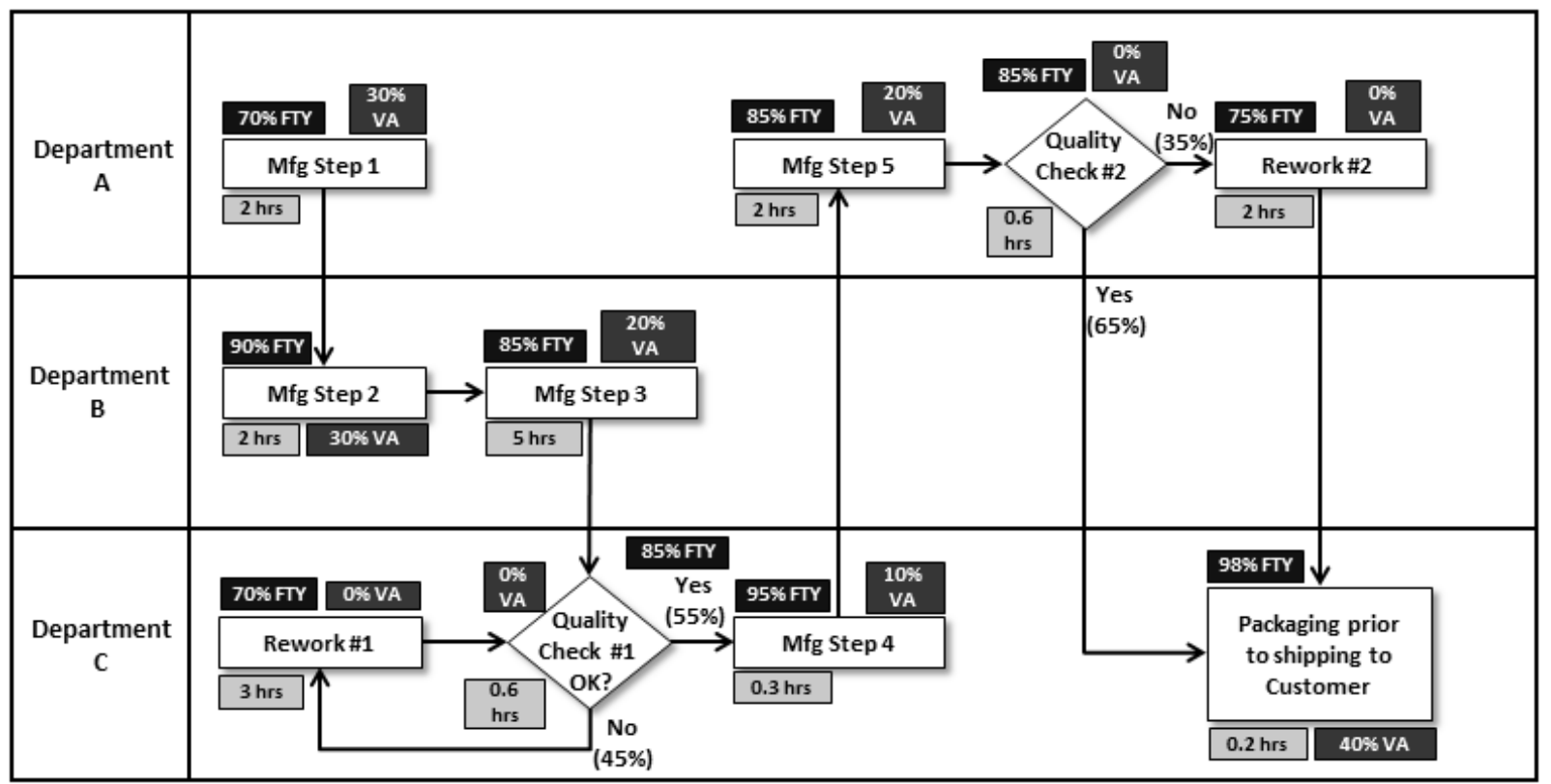

Figure 6: A note is added to each process step and decision to designate the FTY \% for each process and decision.

Source: The Author

\section{- ANALYSIS LAYER \#6: ADD RED BOXES AROUND REDO LOOPS}

The purpose of this layer of analysis is to visually highlight the process steps and decisions that are involved in redoing, repairing and correcting products and services. Show red dotted boxes to depict redo, fix, rework or repair loops in the 
process necessary to correct errors. Also note the average number of times that each redo loop happens. The intent here is to identify how often these redo loops happen so they can be minimized or eliminated in the new and improved process. Figure 7 shows what this process map looks like when redo loops are highlighted with the red boxes.

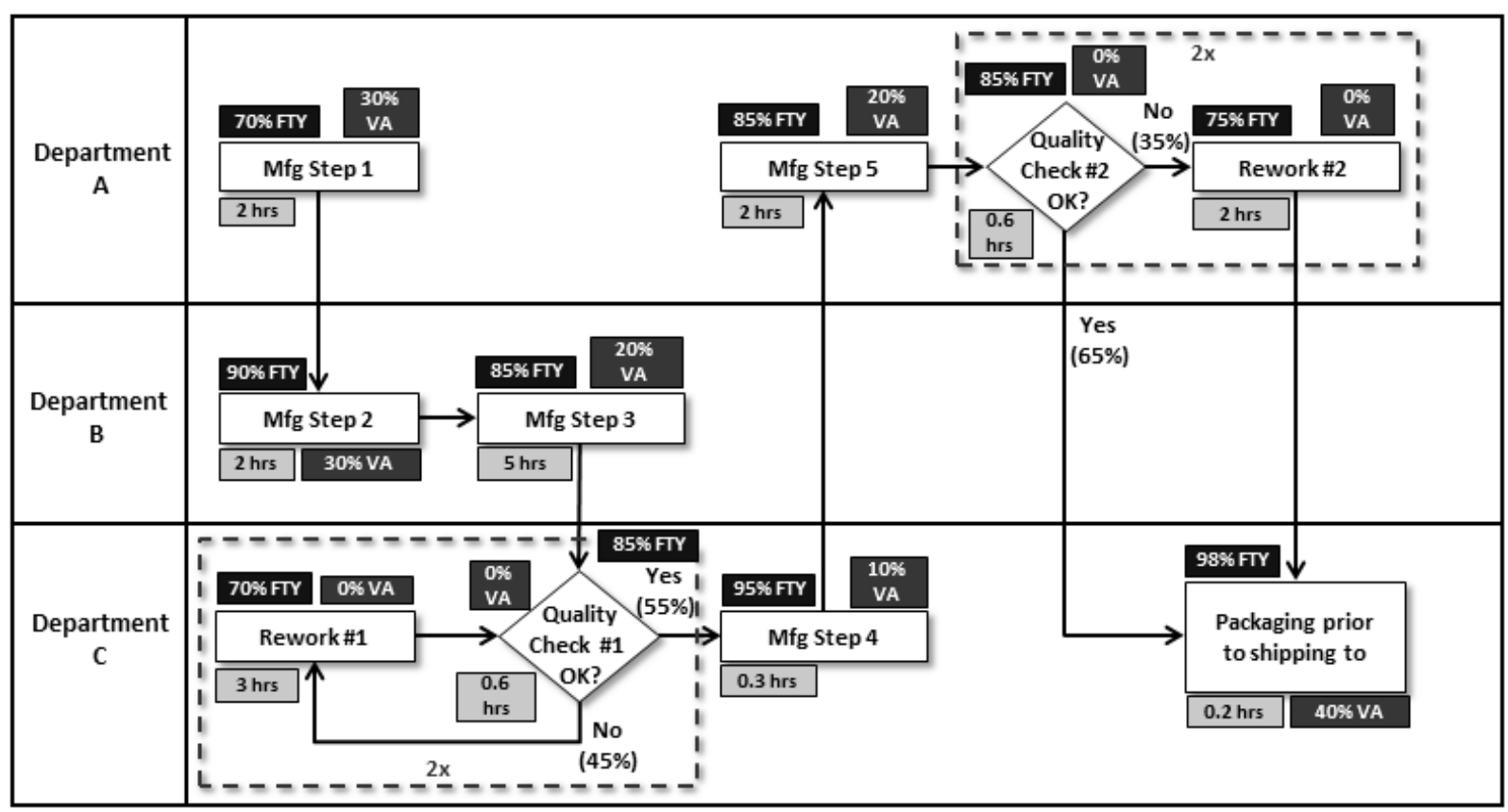

Figure 7: This shows what the process map looks like when 2 redo loops are highlighted with dotted lines and added to the previous process map. Source: The Author

\section{- ANALYSIS LAYER \#7: IDENTIFY WHERE DATA IS BEING COLLECTED IN THE PROCESS}

Note if data is being currently collected for any of the process steps that can be used for process efficiency, trend analysis and performance assessment purposes (See Figure 8). If process data is available, analyze it to learn more about the process efficiency and performance levels over time and use that data to calculate efficiency and performance levels for different customers and products. 


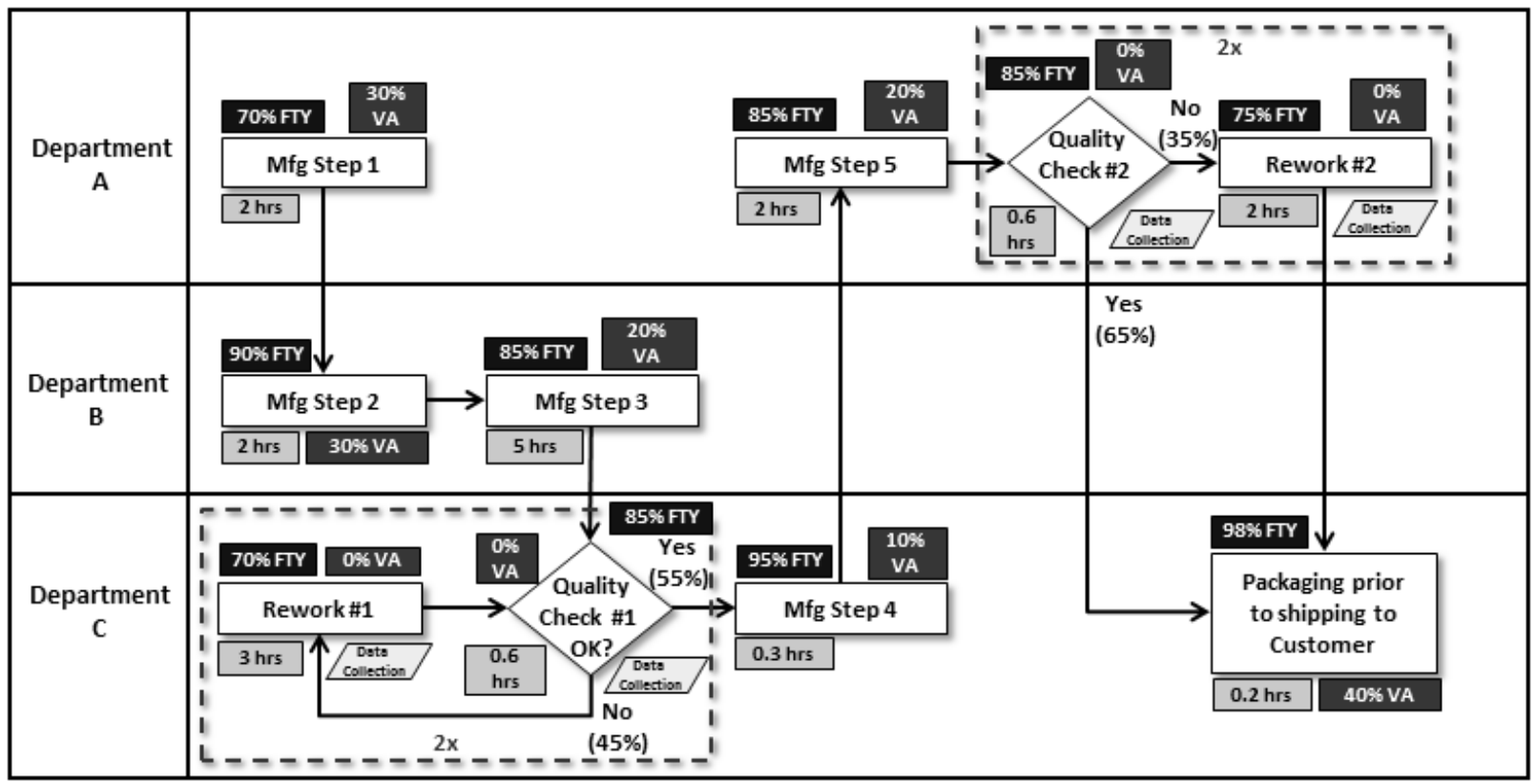

Figure 8: Data collection symbols are now added to show if process data is being collected for the process steps.

Source: The Author

\section{- ANALYSIS LAYER \#8: ADDING INEFFICIENCY ICONS TO REPRESENT THE FORMS OF WASTE AND INEFFICIENCY PRESENT IN THE MANUFACTURING PROCESS}

The purpose of this layer of analysis is to "pictorially" depict the 54 barriers to greatness (54 cards from a unique deck of cards shown in figure 9) and negative chain reactions (Aces, Kings, Queens, jacks and Jokers) that threaten specific business processes.

Larry Bossidy notes that "many people regard execution as detail work that's beneath the dignity of a business leader. That's wrong. To the contrary, it's a leader's most important job" (BOSSIDY, 2002). 13 of the 54 cards in PPA can highlight undisciplined leadership attributes that need to be addressed. Leadership aspects of an organization have a paramount impact on the efficiency of their manufacturing processes. Other process assessment techniques avoid this sensitive issue of Operations Management assessment; PPA does not. Disasters are initiated by selfdestructive and avoidable chain reactions. This layer of analysis is intended to visualize those threats by pasting the specific cards next to the process and decisions in the process map where those risks exist. The 54 elements of risk are pictorially shown in Figure 9. 
Some of the best hands-on and iconic CEOs in the USA, like Jack Welch (GE) and Larry Bossidy (Allied Signal/ Honeywell) have written about their management philosophies and paths they followed that enabled their successes in business leadership (WELCH, 2001), (BOSSIDY, 2002). Jack Welch, at the end of his career, reflects in his book "Jack - Straight from the Gut" (WELCH, 2001) on what made GE a great company. He does not boast much about the great products they made but rather he states: "in the end, I believe we created the greatest people factory in the world, a learning enterprise, with a boundary less culture". Jack Welch knows that if you create great people, great products will follow, so he and GE addressed the root cause (people development), which in turn will drive the creation of great products. Any effective process analysis technique must be able to assess risky cultural issues; PPA does. Jack Welch also states: "I stuck to some pretty basic ideas that worked for me, integrity being the biggest one". PPA also has a card (Ace \#9) that can be used to flag any integrity issues that can have a negative effect on a manufacturing process.

Larry Bossidy's book "Execution - the discipline of getting things done" (BOSSIDY, 2002) talks a lot about the right and wrong management behaviors and attitudes he observed later in his career. He saw manufacturing facilities where "plants were run by accountants instead of production people."

The previously listed 54 barriers to greatness are fully capable of holding organizations back from attaining high levels process efficiency. Figure 9 shows the cards available for use in PPA. For organizations with mature business process management techniques in place, the Ace and King Inefficiency Icons might not be required for the assessment of their organizations. These 54 risk factors also incorporate the philosophy of Deming's 14 Key Principles published in his book "Out of the Crisis" (DEMING, 1982), which are actions required by management first, to signal that they are capable and seriously engaged in the right activities to drive efficiency, stay in business and protect investor interests and employee jobs. These culture-shift activities must be driven by top management.

Frederick Winslow Taylor (TAYLOR, 1911) also noted many strong opinions in his book "The Principles of Scientific Management" where he notes that management should take over all work for which they are better suited for than the workers, stating that in the past almost all of the work and responsibility was thrown upon the workers 
INDEPENDENT JOURNAL OF MANAGEMENT \& PRODUCTION (IJM\&P)

http://www.ijmp.jor.br

V. 4, n. 2, July - September 2013.

ISSN: 2236-269X

DOI: 10.14807/ijmp.v4i2.82

to struggle with. They usually did not have the proper level of expertise or management authority and support to deal with the challenges they were given.

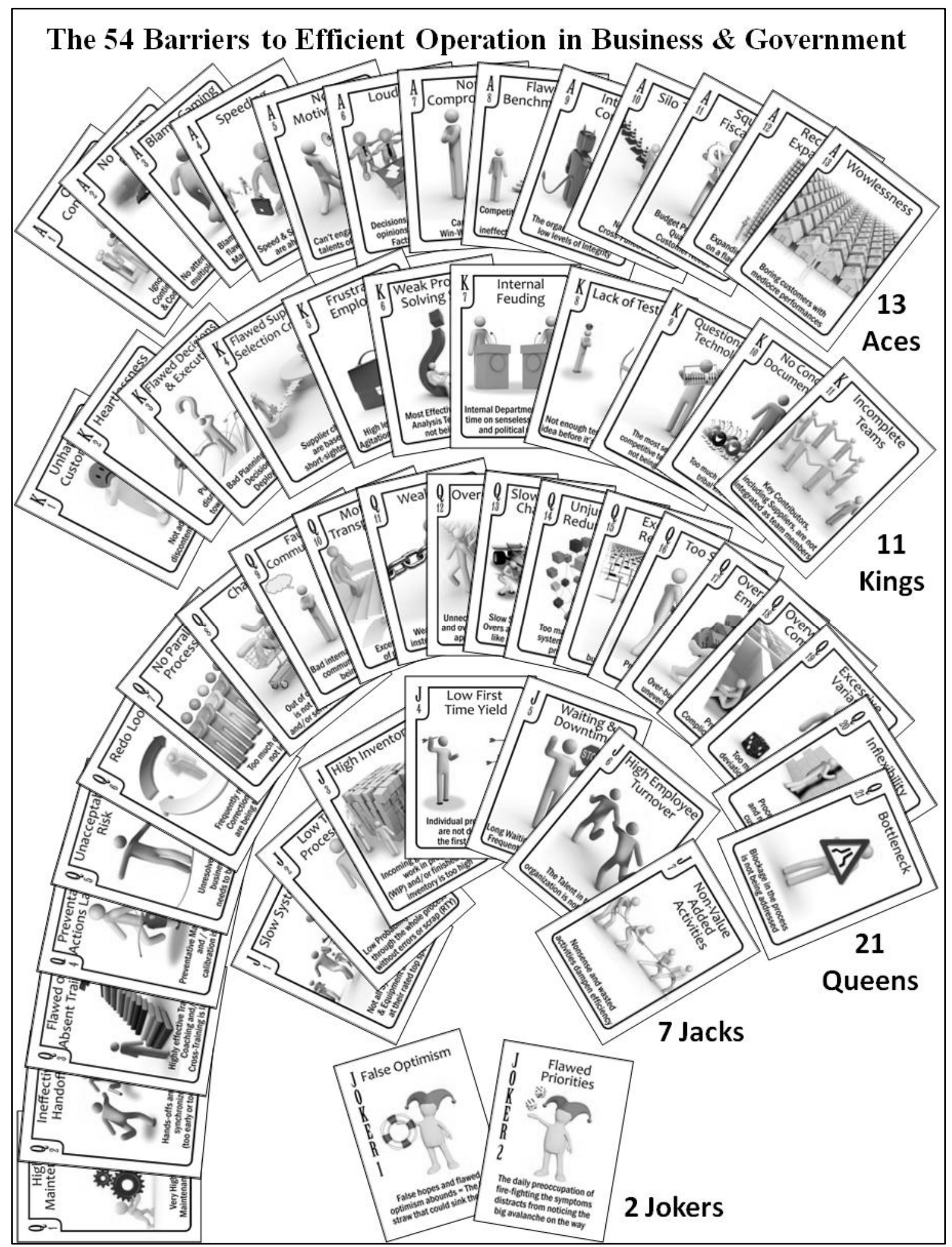

Figure 9: The 54 forms of waste, inefficiency and risk.

Source: The Author

Figure 10 shows what the next level of a PPA process map could look like if all top to bottom aspects of the enterprise were assessed and not only the direct 
DOI: 10.14807/ijmp.v4i2.82

activities in which the production workers are active. The top row of Inefficiency Icons above the process map shows inefficiencies in the operations management. The second row of Inefficiency Icons assesses the weaknesses in the work culture and the resulting organization's overall mode of operation.

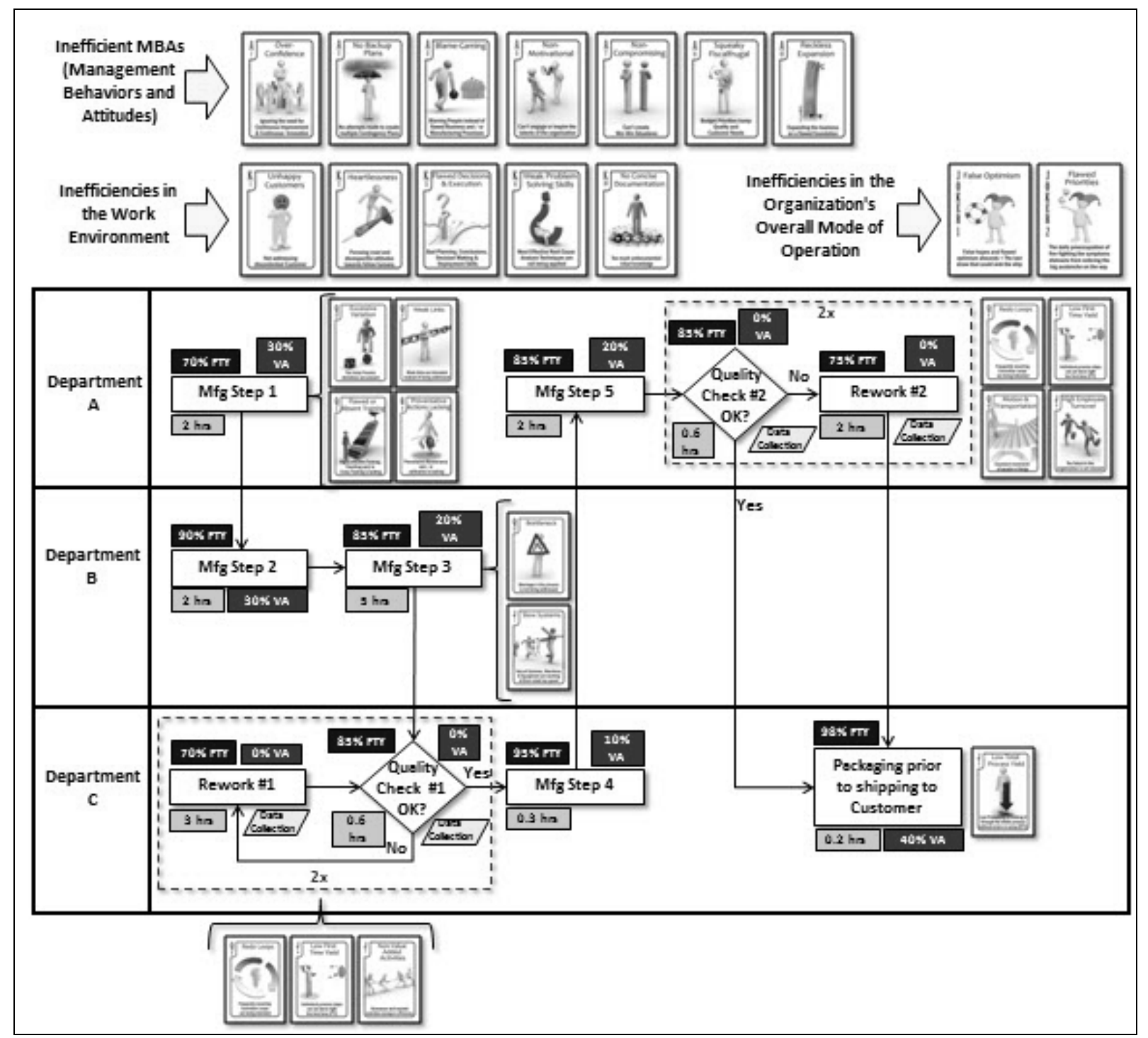

Figure 10: The PPA team now assigns the efficiency risk factors that relate to this manufacturing process.

Source: The Author

The Inefficiency Icons shown inside the process map identify the forms of waste, inefficiency and risk inside this process. The icons above the process map highlight management and cultural issues to address. The purpose of this step in PPA is to visually highlight all of the efficiency barriers and risk factors that the PPA team must address in the new and improved process. 


\title{
- ANALYSIS LAYER \#9: THE TOTAL PROCESS EFFICIENCY SCORECARD
}

A total summarized Process Efficiency Scorecard (Figure 11) should be added at the end of the process mapping analysis, which includes key calculated efficiency performance metrics for the manufacturing process. This particular PPA assessment was supplemented with 3 Inefficiency Icons, which best described the manufacturing process under review. The RTY range shown here of $16-31 \%$ on the scorecard in Figure 11, is the Rolled Throughput Yield. RTY is the result of multiplying all FTY values against each other. RTY is best described as the probability that a product or service will make it through this manufacturing process without being scrapped, reworked or being defective in some way.

This process scorecard is somewhat similar in nature with the Balanced Scorecard (BSC), which was popularized in the 1990s by Bob Kaplan (KAPLAN, 1992) and others.

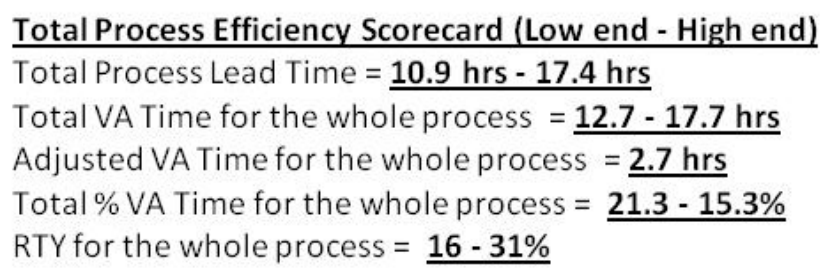

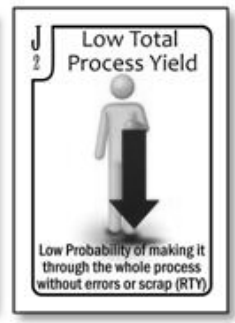
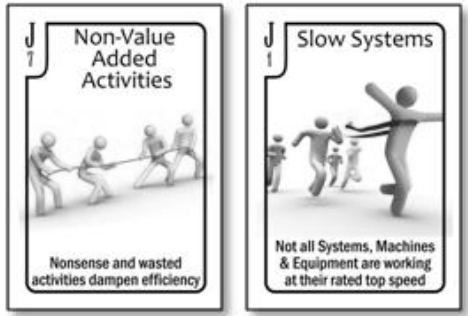

Figure 11: The Process Efficiency Scorecard and Inefficiency Icons that best describe the whole process.

Source: The Author

\section{- ANALYSIS LAYER \#10: AN EXECUTIVE SUMMARY OF THE PROCESS ANALYSIS FINDINGS}

What follows is an example of an executive summary typically used to wrap up the PPA work.

\begin{abstract}
There are various management and work environment inefficiencies that handicap this process and hold it back from greatness. Actual process activity inefficiencies include unsynchronized cycle times, low VA percentage process steps, low First Time Yield (FTY) activities and low quality levels, which result in low internal and external customer satisfaction levels. The organizational fire-fighting efforts are ineffective and only address the symptoms and not the true root causes. This leads to elevated employee stress levels, frustration and high employee turnover.
\end{abstract}

Inefficient Operations Management is the root cause here for the lack of performance stated above. It is not the fault of the employees who work in an 
ineffectively managed process. In the book "Good to Great" (COLLINS, 2001), Jim Collins describes beneficial and reckless management styles that can greatly influence the success or failure of entire companies. The next step for the PPA team would be to create a new and improved process, which is not shown in this paper. That new process map, supplemented with a detailed action plan list, will have to demonstrate how the PPA team will eliminate the waste, efficiencies and risk in the current process.

\section{CREATING THE NEW AND IMPROVED PROCESS}

At the end of a PPA session, the process analysis team should be ready to brainstorm ways to address all of the process weaknesses that have been identified. After that brainstorming exercise, realistic process improvement solutions should be identified for the proposed new and improved process. The proposed new process should also be subjected to the same PPA layers of analysis as the current process was exposed to. Noticeable improvements for all of the layers of analysis should be achieved. If this is not the case, the team brainstorming for improved solutions was not effective. PPA strives to achieve "new and improved" processes, not just "new" processes. After management has approved the improved solutions, the PPA team leader or an experienced program manager should be tasked with rolling out all of the organizational communications, process changes and training required to transform the old process into the new and improved process. This could happen very quickly or over a few weeks or months, depending on the complexity of the changes required.

\section{CONCLUSION}

PPA can create high resolution XRAY pictures of business processes that can be used to accurately assess process efficiency, health, competitiveness and their ability to satisfy internal and external customers. When analyzed correctly with a team of process experts, the current process should be able to achieve vast improvements in cycle time, overall process lead time, error rates, scrap rates, customer satisfaction, value added activities and rolled throughput yield. Vast reductions in process complexity, risk and inefficiency should also be attained. Process mapping can be very effective way to understand, document and optimize business processes. PPA, with its 10 layers of analysis, can offer much more process 
scrutiny and identify many more opportunities for improvement than classic process mapping.

\section{REFERENCES}

BOSSIDY, LARRY (2002), Execution - The Discipline of Getting Things Done, Crown Business / Random House, NY

BRANDT, NATT, (2003), Chicago Death Trap: The Iroquois Theatre Fire Of 1903, Southern Illinois University Press, Southern Illinois University Press, Chicago, III BUNKER, FRANK, GILBRETH, LILLIAN MOLLER GILBRETH (1921) Process Charts. American Society of Mechanical Engineers

COLLINS, JIM (2001), Good to Great, Harper Business, NY

DEMING, WILLIAM E. (1982), Out of the Crisis, Cambridge University Press, Cambridge

DIKOTTER, FRANK, (2010), Mao's Great Famine, Walker Publishing Company, NY GEHMAN, HAROLD, (2003), Columbia Accident Investigation Board, Washington, DC

GILBRETH, FRANK, (1921), Process Charts, ASME, NY

GRAHAM, BOB AND REILLY, WILLIAM, (2012), Deep Water - The Gulf Oil Disaster and the Future, Report to the President, National Commission on the BP Deepwater Horizon Oil Spill and Offshore Drilling, Washington, DC

JURAN, JOSEPH M. (1988), Juran on Planning for Quality, Free Press, New York, NY, USA

KAPLAN, ROBERT S. AND NORTON, DAVID P. (1992), "The Balanced

Scorecard", Harvard Business Review Jan - Feb, 1992

KESWANI, RAJKUMAR, (1984), Wake up people of Bhopal, you are on the edge of a volcano!, Hindi Jansatta daily, http://bhopal.net/an-entirely-avoidable-disaster/, Bhopali, India

MCCARTY, JENNIFER (2008), What Really Sank the Titanic, Citadel Press, NY NTSB - National Transportation Safety Board, (2002), Loss of Control and Impact with Pacific Ocean Alaska Airlines Flight 261 McDonnell Douglas MD-83, Washington, DC

OHNO, TAIICHI (1988), Toyota Production System, Productivity Press, Portland, Oregon

OKTAY, JULIANNE (2012), Grounded Theory, Oxford Press, NY

PATRISHKOFF, DAVID (2010), Training in PPA \& E3 Extreme Enterprise

Efficiency: http://leansixsigmaandbeyond.com/

PATRISHKOFF, DAVID (2012), Pictorial Process Analysis (PPA), Paper presented for the International Conference on Industrial Engineering and Operations Management (ICIEOM'2012), Guimarães, Portugal 
PATRISHKOFF, DAVID (2013), Breaking the Barriers to Greatness, Slideshare, http://www.slideshare.net/davidpatrishkoff/16-slide-pres-of-bt-war-games-for-slideshare

ROGERS, WILLIAM, (1986), Presidential Commission on the Space Shuttle Challenger Accident, Washington, DC

SHINGO, SHINGEO (1986), Zero quality control: The Poka-yoke System, Productivity Press, Portland, Oregon

SMITH, ADAM (1976), The Wealth of Nations, The Works and Correspondence of Adam Smith, Scotland

TAYLOR, FREDERICK WINSLOW (1911), The Principles of Scientific Management, Harper and Bros., New York, NY

The USS Indianapolis Story, (1998), http://www.ussindianapolis.org/intro.htm WANDER, STEVE, NASA Safety Center, (2008) System Failure Case Studies That Sinking Feeling (Petrobras 36 Oil Rig sinking), volume 2, issue 8

WELCH, JACK (2001), Jack - Straight from the Gut, Warner Books, NY WOMACK, JAMES P. (1996), Lean Thinking, Simon \& Schuster, NY XINHAU CHINA NEWS AGENCY, (2005), After 30 years, secrets, lessons of China's worst dams burst accident surface, http://english.people.com.cn/200510/01/eng20051001_211892.html, China 